\title{
Research Paper: Investigating the Efficacy of Sumac Topical Solution Against Permethrin-resistant Human Head Lice
}

\author{
Mohammad Kamalinejad' ${ }^{1}$, Atefe Sharif ${ }^{2}$ Latif Gachkar $^{3}$ Q, Amir Hooshang Ehsani4 ${ }^{4}$, Mahdi Ahmadian-Attar ${ }^{5}$ Q, Mohammad Reza Torabi ${ }^{5}$, Mah-

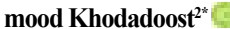 \\ 1. Department of Medicinal Plants, School of Pharmacy, Shahid Beheshti University of Medical Sciences, Tehran, Iran. \\ 2. Department of Traditional Medicine, School of Traditional Medicine, Shahid Beheshti University of Medical Sciences, Tehran, Iran \\ 3. Infectious Diseases and Tropical Medicine Research Center, Shahid Beheshti University of Medical Sciences, Tehran, Iran. \\ 4. Department of Dermatology, School of Medicine, Tehran University of Medical Sciences, Tehran, Iran. \\ 5. Evidence-Based Phytotherapy and Complementary Medicine Research Center, Alborz University of Medical Sciences, Karaj, Iran.
}

\begin{tabular}{|c|c|}
\hline $\begin{array}{l}\text { Use your device to san } \\
\text { and read the article online }\end{array}$ & Citation: Kamalinejad M, Sharif A, Gachkar L, Ehsani AH, Ahmadian-Attar M, Torabi MR, et al. Investigating the Efficacy \\
\hline 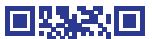 & of Sumac Topical Solution Against Permethrin-resistant Human Head Lice. International Journal of Medical Toxicology and \\
\hline 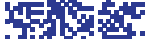 & Forensic Medicine. 2019; 9(3):117-124. https://doi.org/10.32598/ijmtfm.v9i3.25296 \\
\hline atspes & d of : https://doi.org/10.32598/ijmtfm.v9i3.25296 \\
\hline
\end{tabular}

\section{(a) 00}

Article info:

Received: 13 Jan 2019

First Revision: 10 Feb 2019

Accepted: 13 May 2019

Published: 01 Jul 2019

Keywords:

Pediculus, Permethrin, Insecticide-resistance, Rhus coriaria, Sumac

\section{A B STRACT}

Background: The present study aimed at determining the efficacy of applying Rhus coriaria (Sumac) solution for the treatment of Permethrin-resistant head louse in patients, who used permethrin for at least 2 consecutive periods, but have not been cured.

Methods: This study is a before-after clinical trial performed on 100 patients with pediculosis aged between 2 and 50 years old and both sexes. All patients had used Permethrin at least twice consecutively (with at least 14 days interval) according to correct instructions (on the first and $7^{\text {th }}$ day), but they have not been cured. Each patient received $60 \mathrm{ml}$ of Rhus coriaria solution for 3 consecutive days, and the treatment was repeated again for another 3 days; then, the patients were followed-up on the $4^{\text {th }}, 10^{\text {th }}$, and $14^{\text {th }}$ days after the treatment.

Results: The results showed a significant difference in the severity of head lice infection and itching before the treatment and 14 days after the treatment $(\mathrm{P}<0.001)$

Conclusion: Rhus coriaria solution was more effective in eliminating head-louse infestations on 4,10 , and 14 days after the treatment and itching disappeared in most of the patients, while negligible complications were observed.

\section{Introduction}

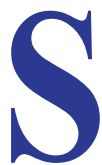

ince more than three decades ago, Ectoparasite populations and head lice have become resistant to all of the drugs including synthetic Pyrethroids [1].
Before the publication of first reports regarding the permethrin resistance in 1990, it was not prescribed [2].These reports were published in France, the Czech Republic,Britain, and Washington State from 1994 to 1998 [1, 3-5]. Resistance to permethrin was reported in the United Kingdom and it had no longer the actual

* Corresponding Author:

Address: Department of Traditional Medicine, School of Traditional Medicine, Shahid Beheshti University of Medical Sciences, Tehran, Iran Tel: +98 (912) 5347582

E-mail: drkhodadoost.m@gmail.com 
practical effectiveness in 1999 [1]; even the prescription of more drug levels was also not effective [2].

Resistance is an advanced mechanism that causes the survival of the insect against a deadly attack. This successful mutation can be transmitted over generations via DNA [2].These resistant organisms can withstand against stimulants and destroyers agents.

Several mechanisms are responsible for permethrin resistance. Permethrin and pyrethroids affect voltagesensitive sodium channel [6]. If these channels get insensitive to these drugs, the treatment will not be effective. Knockdown resistance (Kdr) is one of the most common mechanisms of drug resistance [7].

From 1984 to 1995 , the permethrin efficiency was about $(96 \%)$ to $(100 \%)$. After it was shifted to Over The Counter (OTC), based on the reports, its efficacy reduced to $(80 \%)$ and, then, gradually reduced to $(55 \%)$ and $(28 \%)$, in conditions, where treatments have been completed by nit combing [7]. In the United States, from 1996 to 1999 , the permethrin cure rate was only $(79 \%)$ [8].

Therefore, resistance has been identified as "an upward challenge" that is very terrible, making patients use potentially-harmful treatments like using more powerful or very toxic pesticides, which can be very dangerous for these patients or even cause death because of their side effects. In other words, these hazardous substances and drugs, including Dichloro Diphenyl Trichloroethane (DDT), Oil, Gasoline, and Detergents that have very severe complications, sometimes cause the death of the patients.

In addition, this dilemma will increase costs, drug complications, and the disappointment of treatment, which will lead patients to depression. Studies have shown that because of their low toxicity and fewer complications, the application of plants or herbs can be considered very good alternative pediculicides to be replaced with antilice drugs for the elimination of drug resistance. Therefore, there is a growing interest in using herbs in the treatment of head lice.

The results of a study on the effectiveness of Eucalyptus species on the treatment of permethrin-resistant Pediculus humanus capitis showed that Eucalyptus sideroxylon was more effective than all species [9].

The anti-pediculosis effect of 25 essential oils extracted from different plant species from Argentina, was investi- gated in the treatment of permethrin-resistant head lice. Cinnamomum porphyrium had the most efficacy [10].

In traditional medicine, 120 simple drugs have been named for the topical treatment of head lice, for example, Tamarix gallica oil, as well as 150 compound drugs, for example, the combination of Acorus calamus aromaticus, Cinnamomum Verum, and Carthamus tinctorius oil $[11,12]$. It has been referred to Sumac (Rhus coriaria ) and Olive oil in a book written by Ibn-e-Sina (Al-qanun), Al-Havi, a book written by Razi, and health drugs guidebook written by Ahmed Ali Khosravi [11-13].

Rhus coriaria or Sumac belongs to the Anacardiaceae herbaceous family [14]. It is found in different places of the world, including North Africa and various parts of Iran and Afghanistan [15]. It has been used in traditional medicine and cookery as a spice. In folk medicinal, it has been used for treating diarrhea [14]. Rhus coriaria consists of compounds such as tannins, phenolic acids, flavonoids, terpenoids, and essential oil composed of monoterpenes that have numerous biological activities, which are used as hair cleaning solutions or anti-dandruff agents for the improvement of dermatological problems $[16,17]$. It has antimicrobial, antiviral, antifungal, antioxidant, anti-inflammatory, and anticancer activities [18, 19]; it is also used orally for reducing blood glucose, uric acid, and cholesterol levels [20-22].

Olive oil contains very high amounts of fatty acids and terpenoid species [23]. Even it is used locally for the treatment of head lice; however, in this study, the prepared solution has only low amounts of olive oil, and its main ingredient is Rhus coriaria (Sumac).

The oral and therapeutic uses of these ingredients can be attributed to this fact that they cause no complication [24]. No clinical trial has examined the efficacy of Rhus coriaria solution on pediculosis. This study was conducted as a clinical trial and it evaluated the efficacy and safety of Sumac solution on patients with mild to severe head lice.

\section{Materials and Methods}

The study was conducted in the form of the before-after clinical trial that was performed on 100 patients with pediculosis aged between the range of 2-50 years old and on both sexes. All patients had used permethrin at least for twice consecutively (with at least 14 days interval), according to correct instructions (on the first and seventh day) and they were not treated. The 2 -week study was conducted. 


\section{Inclusion and exclusion criteria}

The inclusion criteria included avoiding depriving patients of routine treatment, patients who had used permethrin treatment twice and more consecutively (with at least 14 days interval) according to the correct instructions (on the first and $7^{\text {th }}$ day) and did not respond to treatment, and yet they had at least grade 1 infection (5-9 nit or live nymphs/lice); they were selected as subjects of the study according to the severity of the contamination [25]. Although the second line of treatment is based on Lindane therapy, the resistance to Lindane is also very high $[2,8]$. Additionally, it causes neurotoxicity and seizure, especially at the younger age; therefore, it has been obsoleted in other countries and its use is not advised $[2,8]$.

The exclusion criteria included: 1 . Any sensitivity to the contents of the solution; 2. Itching and skin ulcers on the head; 3. Secondary skin infection including yellow impetigo and chronic skin diseases such as psoriasis; 4. History of diseases related to immune deficiency; 5 . pregnancy; 6. Participation in any clinical trials within the past 4 weeks or previous participation in this clinical trial $[25,26]$. Obviously, the patients who did not want to continue the cooperation or did not use the medicine in accordance with its correct instructions (the treatment for less than twice every 3 sequential days), or the patients, who used another anti-lice drug simultaneously with the treatment were excluded from the study.

In order to prevent re-infection, other family members, who had head lice, but were not eligible for intervention were also treated with permethrin.

\section{Drug preparation}

Sumac clusters were bought from valid pharmaceuticals market) Buran of Kurdistan) and extra virgin olive oil was bought from Exir company.

The cover of the seeds was separated and placed in boiling water for 4 hours in the lab environment. Then, they passed the finer filters and were poured inside the crystallizer and it was placed on a water bath or set) Bain-Marie machine (for 24 hours. Finally, the dry extract obtained was diluted again with water. Besides, Soy lecithin, as an emulsifier, was gradually added to a very small amount of olive oil and mixed in the clockwise direction. Then, Sumac solution was gradually added to the mixture of Soy lecithin and olive oil. During the addition of the solution, it was rotated slowly clockwise to achieve a monotonic emulsion. The obtained emulsion contained (84.9\%) water and (15.1\%) oils) Olive oil and Soy lecithin). The solution was supplied as a spray to the patients.

\section{Sample size}

$\mathrm{G} *$ power V. 3.1.9.4 (reference number $\mathrm{X}$ ) software was used to analyze the data. The first type error of 0.05 , (95\%) power of the test and the effect size of 0.18 for the statistical test of 2 domains for the sign test of 100 people were calculated for this study according to the following calculations [27].

\section{Data collection method}

Each patient filled out a questionnaire consisting of demographic information such as age, height, weight, BMI, level of education, number of baths per week, number of times for taking shower per a day, number of households, hair color, hair type, and head pruritus [28]. The severity of the complication and the degree of itching were determined and recorded 4 times (day zero and $4^{\text {th }}, 10$ th, and $14^{\text {th }}$ days after treatment). Any complications regarding the use of sumac solution and patient dissatisfaction were also questioned.

The diagnosis was done based on the direct observation of lice or nit. The head was divided into 5 regions by an applicator including the temporal regions and the areas behind the ears and neck [29]; each area was checked by magnifier for infection with lice and nit. Nits locating less than 1.4 inche of the scalp were considered clinically valuable and the rate of infection was graded according to the following division:

1. Zero (0-4 nit); 2 . Grade 1 or mild (5-9 nit or live nymphs/lice); 3 . Grade 2 or medium (10 to 25 nit or live nymphs/lice); 4 . Grade 3 or severe (more than 25 nit or live nymphs/lice) $[25,30]$. All examinations were performed 4 times; once before the treatment (day zero) and 3 times after the start of treatment (days 4, 10, 14). In order to eliminate the diagnostic errors and incorrect evaluation, all examinations were done by only one person (experienced physicians). Clinical symptoms such as pruritus or redness, scalp inflammation, and cervical lymphadenopathy were also evaluated.

\section{Procedure}

The study was conducted in the form of the beforeafter clinical trial. In the intervention group, each patient received $60 \mathrm{ml}$ of solution filled in spray plastic bottles for 3 continuous days, as well as $20 \mathrm{ml}$ daily, by a tiny 
plastic brush teeth. The patients were asked to massage the area after applying the drug each time for 10 minutes on the head and, then, to wrap a towel around their hair and wait for 90 minutes. Then they were asked to comb by a fine brush then washing the hair with water and shampoo. Again, $60 \mathrm{ml}$ of the drug was given to patients to use in 3 continuous days on the $7^{\text {th }}, 8$ th, and $9^{\text {th }}$ days. Patients only used the drug that they were given. They were followed-up on the $4^{\text {th }}, 10^{\text {th }}$, and $14^{\text {th }}$ days of intervention. Patients were examined for lice, nit, and amount of itching or any complications. The information regarding the method of using the drug and the health instructions were given to the patients both in the written and verbal form.

\section{Statistical analysis}

All analyses of baseline and treatment effects were performed, using SPSS V. 22 software and inferential statistics tests (based on the scale of variables, McNemar, Wilcoxon, and the sign test).

\section{Results}

At the beginning of the study, the distribution of severity of head lice infection among 100 patients, who entered the intervention, was as follows: 1. (27\%) of the patients had grade 1 infection; 2 . (41\%) of the patients had grade 2 infec- tion; 3 . (32\%) of them had grade 3 infection. On the $10^{\text {th }}$ day (when the administration of the second dose of the sumac solution was finished), the rate of infection for the patients (27 patients), who had grade 1 infection, was zero. Among 41 patients, who had grade 2 infection, 37 patients reached grade 0 , and 2 patients reached grade 1 , and the status of 2 patients did not change. Among 32 patients, who had grade 3 infection, 19 patients were fully treated, 5 patients reached grade 2 , and 8 patients reached grade 1 . The results of the Wilcoxon Signed Ranks test showed a significant difference in the severity of the infection before the treatment and 10 days after treatment $(\mathrm{P}<0.001)$. Table 1 presents the results of the comparison of the infection rate before the treatment and on the $10^{\text {th }}$ day.

Finally, on the $14^{\text {th }}$ day of the treatment, among 100 patients, $(88 \%)$ of the patients reached grade zero (totally cured), $(7 \%)$ of them reached grade 1 , and $(5 \%)$ of them reached grade 2 . As a result, $(88 \%)$ of the patients were fully treated and the rate of infection reduced to $(12 \%)$, and $(5 \%)$ of them reached grade 2 and $(7 \%)$ of them reached grade 1.

The results of the Wilcoxon Signed Ranks test showed a significant difference in the severity of the infection before the treatment and 14 days after treatment $(\mathrm{P}<0.001)$. Table 2 presents the results of the comparison of the infection rate before the treatment and on the $14^{\text {th }}$ day.

Table 1. Comparison of the grade of infection before the treatment and on the $10^{\text {th }}$ day

\begin{tabular}{|c|c|c|c|c|c|}
\hline \multirow{2}{*}{\multicolumn{2}{|c|}{ Grade }} & \multicolumn{3}{|c|}{ The Grade of Infection After Treatment (10 $10^{\text {th }}$ day) } & \multirow{2}{*}{ Total } \\
\hline & & Zero (1-4) & One (5-9) & Two (10-24) & \\
\hline \multirow{3}{*}{$\begin{array}{l}\text { The grade of infection } \\
\text { before } \\
\text { treatment (first day) }\end{array}$} & One (5-9) & 27 & 0 & 0 & 27 \\
\hline & Two (10-24) & 37 & 2 & 2 & 41 \\
\hline & Three (>25) & 19 & 8 & 5 & 32 \\
\hline \multicolumn{2}{|c|}{ Total } & 83 & 10 & 7 & 100 \\
\hline
\end{tabular}

Table 2. Comparison of the grade of infection before the treatment and on the $14^{\text {th }}$ day

\begin{tabular}{|c|c|c|c|c|c|}
\hline \multicolumn{2}{|c|}{ Grade } & \multicolumn{3}{|c|}{ The Grade of Infection After Treatment (14 ${ }^{\text {th }}$ day) } & \multirow{2}{*}{ Total } \\
\hline & & Zero (1-4) & One (5-9) & Two (10-24) & \\
\hline \multirow{3}{*}{$\begin{array}{l}\text { The grade of infection } \\
\text { before } \\
\text { treatment (first day) }\end{array}$} & One (5-9) & 27 & 0 & 0 & 27 \\
\hline & Two (10-24) & 38 & 3 & 0 & 41 \\
\hline & Three $(>25)$ & 23 & 4 & 5 & 32 \\
\hline \multicolumn{2}{|c|}{ Total } & 88 & 7 & 5 & 100 \\
\hline
\end{tabular}


Table 3. Comparison of the rate of itching before the treatment and on the $4^{\text {th }}$ day

\begin{tabular}{|c|c|c|c|c|c|c|c|}
\hline \multirow{2}{*}{\multicolumn{2}{|c|}{ Rate }} & \multicolumn{5}{|c|}{ After the Treatment (The $4^{\text {th }}$ day) } & \multirow{2}{*}{ Total } \\
\hline & & 0 & Low & Medium & high & Very high & \\
\hline \multirow{5}{*}{$\begin{array}{l}\text { Before the treatment } \\
\text { (the first day) }\end{array}$} & 0 & 17 & 0 & 0 & 0 & 0 & 17 \\
\hline & Low & 12 & 0 & 0 & 0 & 0 & 12 \\
\hline & medium & 8 & 18 & 1 & 0 & 0 & 37 \\
\hline & high & 4 & 7 & 5 & 0 & 0 & 16 \\
\hline & Very high & 9 & 2 & 4 & 2 & 1 & 18 \\
\hline \multicolumn{2}{|c|}{ Total } & 60 & 27 & 10 & 2 & 1 & 100 \\
\hline
\end{tabular}

Table 4. Comparison of the rate of itching before the treatment and on the $14^{\text {th }}$ day

\begin{tabular}{|c|c|c|c|c|c|c|c|}
\hline \multirow{2}{*}{\multicolumn{2}{|c|}{ Itching Rate }} & \multicolumn{5}{|c|}{ After the Treatment (The $4^{\text {th }}$ day) } & \multirow{2}{*}{ Total } \\
\hline & & 0 & Low & Medium & high & Very high & \\
\hline \multirow{5}{*}{$\begin{array}{l}\text { Before the treatment } \\
\text { (the first day) }\end{array}$} & 0 & 17 & 0 & 0 & 0 & 0 & 17 \\
\hline & Low & 12 & 0 & 0 & 0 & 0 & 12 \\
\hline & medium & 34 & 3 & 0 & 0 & 0 & 37 \\
\hline & high & 12 & 3 & 1 & 0 & 0 & 16 \\
\hline & Very high & 14 & 2 & 0 & 1 & 1 & 18 \\
\hline \multicolumn{2}{|c|}{ Total } & 89 & 8 & 1 & 1 & 1 & 100 \\
\hline
\end{tabular}

Surprisingly, itching reduced in the patients after the $4^{\text {th }}$ day. Itching completely eliminated in $(33 \%)$ of the patients; $(27 \%)$ of them had only slight itching, (10\%) of them had moderate itching, and $(3 \%)$ of the patients had still high or very high itching. Table 3 shows the rate of itching before treatment and on the $4^{\text {th }}$ day.

On the $10^{\text {th }}$ day of the treatment, $(86 \%)$ of the patients had no itching at all, (11\%) of the patients had a little itching, and (1\%) of the patients had medium, high, or very high itching. Finally, on the $14^{\text {th }}$ day of the treatment, $(89 \%)$ of the patients had no itching, $(8 \%)$ of them had low pruritus, and ( $1 \%)$ of them had moderate itching. Only $(2 \%)$ of the patients had high and very high pruritus. Table 4 presents the rate of itching before the treatment and on the $14^{\text {th }}$ day.

\section{Discussion}

There was a significant difference in the severity of pediculosis before and after the treatment, and the rate of itching of the head became none or significantly less.

Seemingly, increasing the dose of the solution or the duration of using the solution would yield better results. The patients' satisfaction of treatment was very high and significant, while the side effects of the solution were negligible and included only burning and pruritus in the first 1 to 2 minutes after the use of the drug in some patients. In the patient's follow-up, a large number of subjects did not have pediculosis for several months, while in the case of using other drugs, they could not get rid of pediculosis at all, or they were quickly re-infected.

This indicates the strength of the drug in terms of its function, including the important effect of topical cleansing of the scalp and making the environment inappro- 
priate for the continuation of the life of the insect. This event could result from the presence of tannin in sumac. Sumac contains a large number of tannins that have a tannery effect and cleansing effect that make the environment of scalp unpleasant for the life of the insect; it can remove the thick and sticky material underneath the scalp and clear the crust of substances, which accumulate in the pores of the skin and hair follicles. Therefore, most of the patients did not suffer from pediculosis for several months later.

Many studies have investigated the administration of herbal medicines for the treatment of head lice, but the use of sumac and olive oil, both of which had a long history in nutrition, seems to reduce the concerns about drug toxicity or complications, especially for long and frequent uses.

All patients, who entered the intervention, had used permethrin for at least 2 continuous periods and they did not positively respond to treatment. Most patients coexisted for a long time with lice and they did not get rid of the insect and nit at all and they had used other therapies including Lindane and Dimethicone lotion (4\%) (Dilice), DDT, Gasoline, Oil, Mayonnaise, and Detergent. Today, pediculosis is widely spread and it has passed the economic, cultural, and health border; as it is widely seen in all societies, finding a suitable treatment is very necessary.

The limitations of the study include the lack of awareness of the patients, especially the students and their families, about the importance of treatment, follow-up, and the lack of cooperation between school and health care providers.

\section{Conclusion}

The results of this study demonstrate that Sumac solution can be a safe and effective solution for the treatment of head lice and can prevent drug resistance, cost increases, and confusion and frustration among the patients.

\section{Ethical Considerations}

\section{Compliance with ethical guidelines}

Patients who were consent to participate in the intervention filled out the form of ethics consent, and the parents of patients aged under 18 years old also filled out the consent form . The study protocol was approved by the Ethics Committee of Shahid Beheshti University of Medical Sciences (IR.SBMU.RETECH.REC.1397.125) and was registered in the Iranian Registry of Clinical Trials (IRCT20180712040446N1).

\section{Funding}

This article is based on $\mathrm{PhD}$ thesis Number 207 School of Traditional Medicine, Shahid Beheshti University of Medical Sciences, Tehran, Iran.

\section{Author's contributions}

Conceptualization: Mohammad Kamalinejad, Atefe Sharif, Mahmood Khodadoost, Amir Hooshang Ehsani; Methodology: Latif Gachkar, Mohammad Kamalinejad, Atefe Sharif; Investigation: Mohammad Kamalinejad, Mahmood Khodadoost, Amir Hooshang Ehsani; Writing-original draft: Atefe Sharif, Mohammad Kamalinejad; Writing-review \& editing: Mohammad Kamalinejad, Latif Gachkar, Mahmood Khodadoost, Amir Hooshang Ehsani; Funding acquisition: Mohammad Kamalinejad, Mahmood Khodadoost, Mahdi Ahmadian-Attar, Mohammad Reza Torabi; Supervision: Mohammad Kamalinejad, Atefe Sharif, Mahmood Khodadoost, Amir Hooshang Ehsani; Project administration: Mahmood Khodadoost, Atefe Sharif; Data curation: Latif Gachkar, Atefe Sharif; Approval of the version of the manuscript to be published: Mohammad Kamalinejad, Atefe Sharif, Latif Gachkar, Mahmood Khodadoost, Amir Hooshang Ehsani, Mahdi Ahmadian-Attar, Mohammad Reza Torabi.

\section{Conflict of interest}

The authors declared no conflict of interest.

\section{Acknowledgments}

The authors would like to acknowledge Shahid Beheshti center for research cooperation and financial support.

\section{References}

[1] McNair CM. Ectoparasites of medical and veterinary importance: Drug resistance and the need for alternative control methods. Journal of Pharmacy and Pharmacology. 2015; 67(3):351-63. [DOI:10.1111/jphp.12368] [PMID]

[2] Steven Pray W. Consult your pharmacist-head lice: New approaches may help overcome pediculicide resistance-growing resistance to many forms of treatment makes this parasite hard to eradicate. US Pharmacist. 2010; 35(3):10. 
[3] Rupes V, Moravec J, Chmela J, Ledvinka J, Zelenkova J. A resistance of head lice (Pediculus capitis) to permethrin in Czech Republic. Central European Journal of Public Health. 1995; 3(1):30-2. [PMID]

[4] Burgess IF, Brown CM, Peock S, Kaufman J. Head lice resistant to pyrethroid insecticides in Britain. British Medical Journal. 1995; 311(7007):752. [DOI:10.1136/bmj.311.7007.752] [PMID] [PMCID]

[5] Bell TA. Treatment of Pediculus humanus var. capitis infestation in Cowlitz County, Washington, with ivermectin and the LiceMeister $₫$ comb. The Pediatric Infectious Disease Journal. 1998; 17(10):923-4. [DOI:10.1097/00006454-19981000000017] [PMID]

[6] Gao J-R, Yoon KS, Frisbie RK, Coles GC, Clark JM. Esterase-mediated malathion resistance in the human head louse, Pediculus capitis (Anoplura: Pediculidae). Pesticide Biochemistry and Physiology. 2006; 85(1):28-37. [DOI:10.1016/j. pestbp.2005.09.003]

[7] Gellatly KJ, Krim S, Palenchar DJ, Shepherd K, Yoon KS, Rhodes CJ, et al. Expansion of the knockdown resistance frequency map for human head lice (Phthiraptera: Pediculidae) in the United States using quantitative sequencing. Journal of Medical Entomology. 2016; 53(3):653-9. [DOI:10.1093/jme/ tjw023] [PMID] [PMCID]

[8] Durand R, Bouvresse S, Berdjane Z, Izri A, Chosidow O, Clark J. Insecticide resistance in head lice: Clinical, parasitological and genetic aspects. Clinical Microbiology and Infection. 2012; 18(4):338-44. [DOI:10.1111/j.1469-0691.2012.03806.x] [PMID]

[9] Toloza AC, Lucía A, Zerba E, Masuh H, Picollo MI. Eucalyptus essential oil toxicity against permethrin-resistant Pediculus humanus capitis (Phthiraptera: Pediculidae). Parasitology Research. 2010; 106(2):409. [DOI:10.1007/s00436-009-1676-6] [PMID]

[10] Toloza AC, Zygadlo J, Biurrun F, Rotman A, Picollo MI. Bioactivity of argentinean essential oils against permethrinresistant head lice, Pediculus humanus capitis. Journal of Insect Science. 2010; 10(1):185. [DOI:10.1673/031.010.14145] [PMID] [PMCID]

[11] Muhammad ibn Zakariya al-Razi. [Al-Hawi: Comprehensive book of medicine, volume 7 (Al-Hawi fi'l-tibb) (Arabic)]. Beirut: Dar al-Ahiya' Altrah al-Arabi; 1422 AD.

[12] Ibn-e-Sina A. [The Canon of medicine, volume 4 (Al-qanun fit-tib) (Arabic)]. Beirut: 1426 AD.

[13] Khosravi AA. [Health Drugs Guidebook (Persian)]. Tehran: Iran University of Medical Sciences Publication; 2007.

[14] Rawashdeh IM, Ghzawi AL, Rawashdeh NQ, Khairallh K, Al-Tawaha AR, Salama B. Genetic variation among sumac (Rhus Coriaria L.) samples collected from three locations in Jordan as revealed by AFLP markers. Advances in Environmental Biology. 2009; 3(1):107-12.

[15] Ahmadian-Attari M, Amin G, Fazeli MR, Jamalifar H. A review on antimicrobial activities of sumac fruit (Rhus Coriaria L.). Journal of Medicinal Plants. 2008; 1(25):1-11.

[16] Abu-Reidah IM, Ali-Shtayeh MS, Jamous RM, ArráezRomán D, Segura-Carretero A. HPLC-DAD-ESI-MS/MS screening of bioactive components from Rhus Coriaria L. (Su- mac) fruits. Food Chemistry. 2015; 166:179-91. [DOI:10.1016/j. foodchem.2014.06.011] [PMID]

[17] Farag MA, Fayek NM, Reidah IA. Volatile profiling in Rhus Coriaria fruit (sumac) from three different geographical origins and upon roasting as analyzed via solid-phase microextraction. PeerJ. 2018; 6:e5121. [DOI:10.7717/peerj.5121] [PMID] [PMCID]

[18] Kacergius T, AbuLafi S, Kirkliauskiene A, Gabe V, Adawi A, Rayan M, et al. Inhibitory capacity of Rhus Coriaria L. extract and its major component methyl gallate on Streptococcus mutans biofilm formation by optical profilometry: Potential applications for oral health. Molecular Medicine Reports. 2017; 16(1):949-56. [DOI:10.3892/mmr.2017.6674] [PMID]

[19] Salimi Z, Eskandary A, Headari R, Nejati V, Moradi M, Kalhori Z. Antioxidant effect of aqueous extract of sumac (Rhus Coriaria L.) in the alloxan-induced diabetic rats. Indian Journal of Physiology and Pharmacology. 2015; 59(1):87-93.

[20] Pourahmad J, Eskandari MR, Shakibaei R, Kamalinejad M. A search for hepatoprotective activity of aqueous extract of Rhus Coriaria L. against oxidative stress cytotoxicity. Food and Chemical Toxicology. 2010; 48(3):854-8. [DOI:10.1016/j. fct.2009.12.021] [PMID]

[21] Alghadir A, Gabr S. Efficacy of Rhus Coriaria (Sumac) juice in reducing muscle pain during aerobic exercise. Acta Physiologica Hungarica. 2016; 103(2):231-42. [DOI:10.1556/036.103.2016.2.10] [PMID]

[22] Nazouri Mahdabadi M, Khabjavid Z, Tafakori Baghdarian N, Lookian F, Javid A, Mousavi SH, et al. RhusCoriaria effect on serum uric acid level and in vivo xanthine oxidase activity in oxonate-induced hyperuricemic mice. Journal of Pharmaceutical and Biomedical Sciences. 2013; 3(12):1-6.

[23] Muço M, Kopali A, Muço LX. Physical and chemical characteristics of olive oils from autochthonous Albanian olive varieties. Journal of Hygienic Engineering and Design. 2015; 12:60-5.

[24] Yan J, Oey SB, van Leeuwen SP, van Ruth SM. Discrimination of processing grades of olive oil and other vegetable oils by monochloropropanediol esters and glycidyl esters. Food Chemistry. 2018; 248:93-100. [DOI:10.1016/j.foodchem.2017.12.025] [PMID]

[25] Wolf L, Eertmans F, Wolf D, Rossel B, Adriaens E. Efficacy and safety of a mineral oil-based head lice shampoo: A randomized, controlled, investigator-blinded, comparative study. PloS One. 2016; 11(6):e0156853. [DOI:10.1371/journal. pone.0156853] [PMID] [PMCID]

[26] Bowles VM, VanLuvanee LJ, Alsop H, Hazan L, Shepherd $\mathrm{K}$, Sidgiddi S, et al. Clinical studies evaluating abametapir lotion, $0.74 \%$, for the treatment of head louse infestation. Pediatric Dermatology. 2018; 35(5):616-21. [DOI:10.1111/pde.13612] [PMID] [PMCID]

[27] Faul F, Erdfelder E, Lang A-G, Buchner A. G* Power 3: A flexible statistical power analysis program for the social, behavioral, and biomedical sciences. Behavior Research Methods. 2007; 39(2):175-91. [DOI:10.3758/BF03193146]

[28] Abdolhosseini S, Mokaberinejad R, Alian Nezhadi V, Bozorgi M, Nazem E. Evaluation of treatment with Squill Vinegar in 10 patients with Head Pediculosis. Asian Journal of Clinical Case Reports for Traditional and Alternative Medicine. $2017 ;$ 1(1):57-64. 
[29] Meister L, Ochsendorf F. Head lice: Epidemiology, biology, diagnosis, and treatment. Deutsches Ärzteblatt International. 2016; 113(45):763. [DOI:10.3238/arztebl.2016.0763] [PMID] [PMCID]

[30] Cummings C, Finlay JC, MacDonald NE. Head lice infestations: A clinical update. Paediatrics \& Child Health. 2018, 23(1):e18-e24. [DOI:10.1093/pch/pxx165] [PMID] [PMCID] 